\title{
MODELO DE SIMULAÇÃo ESTOCÁSTICA DA RECARGA DE VEÍCULOS ELÉTRICOS EM REDES DE DISTRIBUIÇÃO DE ENERGIA
}

\author{
Windson Braga Pereira \\ UERJ - Universidade do Estado do Rio de Janeiro \\ LSPV - Laboratório de Sistemas de Propulsão Veicular e Fontes Eletroquímicas \\ Rua Fonseca Teles, 121, Bloco Anexo, Sala L - 15, São Cristóvão - RJ \\ windsonbraga@hotmail.com \\ Luiz Artur Pecorelli Peres \\ UERJ - Universidade do Estado do Rio de Janeiro \\ LSPV - Laboratório de Sistemas de Propulsão Veicular e Fontes Eletroquímicas \\ lapp_uerj@yahoo.com.br \\ José Francisco Moreira Pessanha \\ UERJ - Universidade do Estado do Rio de Janeiro \\ IME - Instituto de Matemática e Estatística \\ Rua São Francisco Xavier, 524, Bloco F, $6^{\circ}$ Andar, Maracanã - RJ \\ professorjfmp@hotmail.com
}

\begin{abstract}
RESUMO
Este trabalho apresenta um modelo de simulação para avaliação da recarga de veículos elétricos em redes de distribuição de energia com foco na adequação da capacidade dos transformadores. Com base em medições efetuadas foi possível o tratamento dos dados para a modelagem dos impactos do acréscimo desta demanda em transformadores de distribuição. O modelo de simulação permite avaliar o efeito de variáveis aleatórias relacionadas às distâncias previamente percorridas pelos veículos bem como ao instante da sua conexão à rede elétrica. Estes efeitos foram comparados considerando estas variáveis em termos determinísticos e permitiram concluir a importância da utilização destes métodos mais realistas para calcular a capacidade dos transformadores visando suprir esta nova demanda.
\end{abstract}

Palavras-chave: Recarga de Veículos Elétricos, Simulação, Redes Inteligentes.

\begin{abstract}
This paper presents an simulation model of recharging electric vehicles in power distribution networks focused on the adequacy of the transformers capacity. Based on developed measurements was possible the processing of data for modeling the impacts of this demand increase in distribution transformers. The simulation model allows evaluate the effect of random variables related to the distances traveled by vehicles previously and the moment of its connection to the grid. These effects were compared considering these variables in deterministic terms and it became possible to understand the importance of using these more realistic methods to calculate the capacity of transformers for supplying this new demand.
\end{abstract}

Keywords: Recharging of Electric Vehicles, Simulation, Smart Grid. 


\section{Introdução}

No contexto do projeto de P\&D "Desenvolvimento de Rede de Abastecimento de Veículos Elétricos para a Cidade Inteligente Búzios“ foram desenvolvidos protótipos de painéis de recarga que se destinam à coleta de dados no Centro de Monitoramento e Pesquisa - CMP da Ampla Energia e Serviços S/A em Búzios. Estes painéis permitem uma operação segura dos usuários obedecendo às normas técnicas vigentes, bem como a demonstração aos visitantes das medições em tempo real que podem ser efetuadas com os mesmos, visando analisar o desempenho dos veículos (PECORELLI PERES et al, 2014). Devido à necessidade de maior eficiência energética dos meios de transporte rodoviário a penetração de veículos elétricos a bateria vem alcançando taxas de crescimento em vários países uma vez que o ingresso desta tecnologia se mostra bem mais sustentável em comparação com veículos tradicionais a combustão interna. Todavia, torna-se uma preocupação paras empresas de energia elétrica a avaliação da capacidade das redes visando evitar sobrecargas pontuais, em especial nos transformadores de distribuição (SERRA, 2012).

Neste sentido, o artigo está inserido nas atividades de pesquisa do Laboratório de Sistemas de Propulsão Veicular e Fontes Eletroquímicas - LSPV da UERJ que participa do projeto "Desenvolvimento de Rede de Abastecimento de Veículos Elétricos para a Cidade Inteligente Búzios", em parceria com a empresa Ampla Energia e Serviços de Eletricidade S.A. sob os auspícios da Agência Nacional de Energia Elétrica - ANEEL.

Com base em procedimentos de testes de recarga de carros elétricos desenvolvidos pelo LSPV foi possível o registro e o tratamento dos dados para a modelagem dos impactos do acréscimo desta demanda em intervalos de tempo discretos correspondentes à medição efetuada pelas empresas de energia elétrica (PECORELLI PERES et al, 2009). O veículo utilizado nos ensaios de recarga foi o Palio Weekend Elétrico montado pela Itaipu Binacional através de acordo de cooperação tecnológica com a KWO - Kraftwerke Oberhasli AG da Suíça em parceria com a Fiat do Brasil e cujo processo de recarga da bateria é realizado através de um carregador interno ao veículo. No artigo apresenta-se um modelo de simulação que permite avaliar o efeito das variáveis aleatórias relativas ao instante da conexão do veículo à rede elétrica e à distância previamente percorrida pelo veículo. Estes efeitos foram comparados considerando estas variáveis em termos determinísticos e permitiram concluir a importância da utilização de métodos mais realistas para estimar a capacidade de folga dos transformadores (FREUND et al, 1969)

\section{Resultados de Testes de Recarga de Veículo Elétrico}

A modelagem pretendida utilizou os resultados dos ensaios de recarga procedidos pelo LSPV/UERJ com um Palio Weekend Elétrico. A Tabela 1 abaixo mostra os dados do banco de baterias do Palio Weekend Elétrico.

Tabela 1 - Dada da bateria do Palio Weekend Elétrico

\begin{tabular}{c|c|c}
\hline $\begin{array}{c}\text { Tensão Nominal } \\
(\mathrm{V})\end{array}$ & $\begin{array}{c}\text { Capacidade } \\
(\mathrm{Ah})\end{array}$ & $\begin{array}{c}\text { Rendimento do conjunto } \\
\text { bateria }- \text { carregador }\end{array}$ \\
\hline 253 & 76 & 0,95 \\
\hline
\end{tabular}


Foram realizados ensaios de trajeto em diversos percursos seguidos pelas recargas efetuadas com o Palio Weekend Elétrico. Por exemplo foi selecionado o trajeto de $9 \mathrm{~km}$ com a bateria do veículo inicialmente com 100\% da carga. Durante a recarga mediu-se a tensão, a corrente, o fator de potência, as potências ativa, reativa e aparente. A Tabela 2 e as Figuras 1 a 3 apresentam, respectivamente, os valores medidos e os gráficos referente aos resultados do teste de recarga realizada pelo LSPV utilizando registrador de grandezas elétricas, modelo MARH-21/993, fabricado pela RMS.

Tabela 2 - Valores medidos durante o teste de recarga

\begin{tabular}{c|c|c}
\hline $\begin{array}{c}\text { Tempo de Recarga } \\
(\mathrm{min})\end{array}$ & $\begin{array}{c}\text { Energia Acumulada } \\
(\mathrm{kWh})\end{array}$ & $\begin{array}{c}\text { Potência Média Máxima } \\
(\mathrm{kW})\end{array}$ \\
\hline 53 & 1,9395 & 3,25 \\
\hline
\end{tabular}

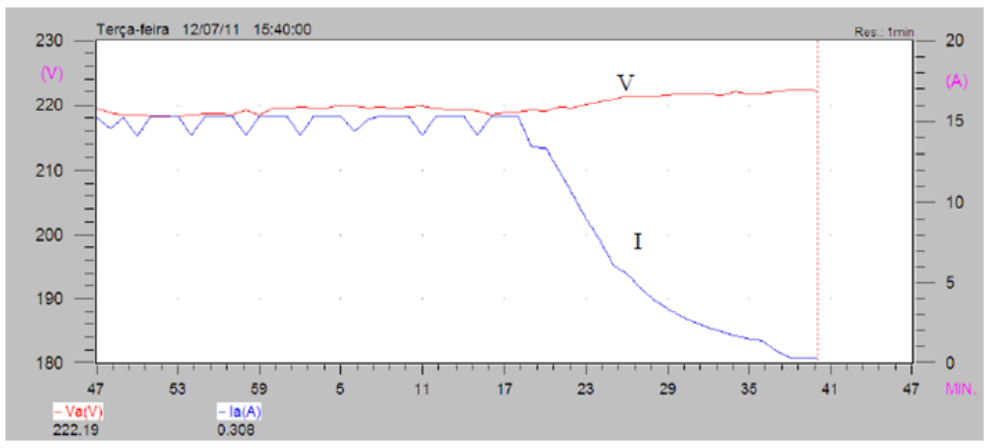

Figura 1 - Tensão e corrente de recarga

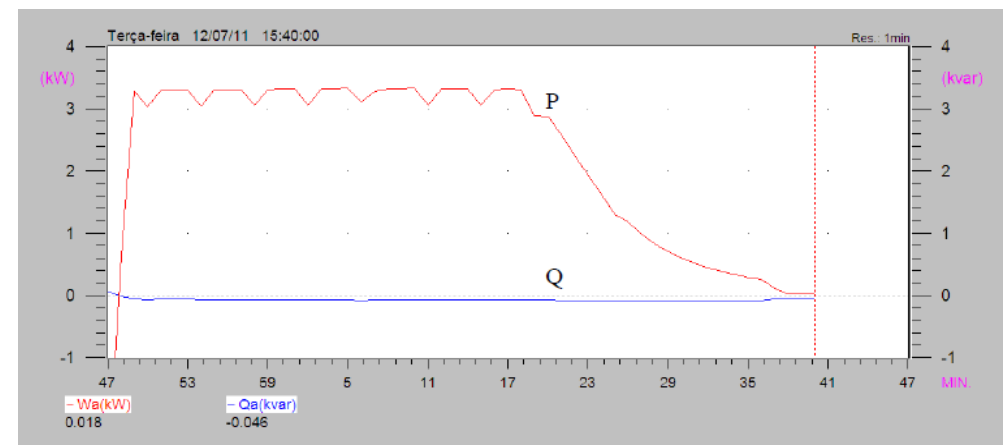

Figura 2 - Potências ativa e reativa da recarga do veículo

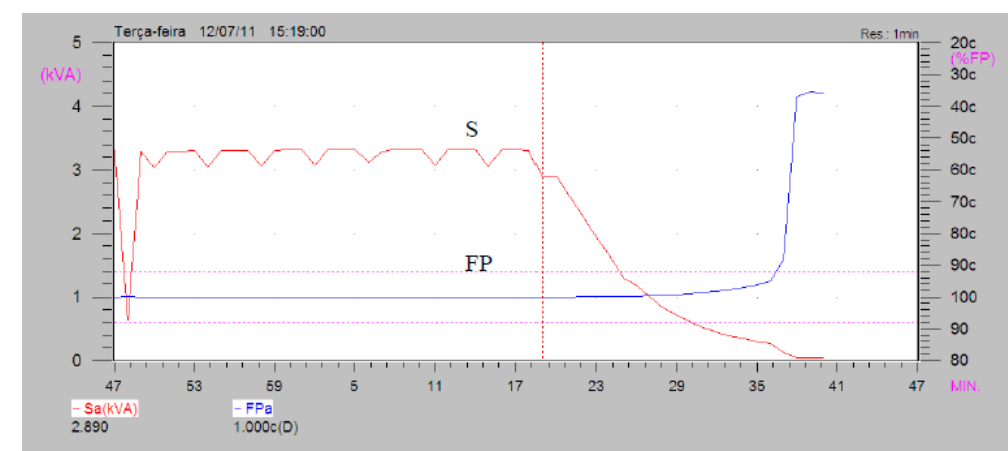

Figura 3 - Potência aparente e fator de potência da recarga do veículo

\section{Modelagem da Curva de Recarga de Veículos Elétricos}


Os testes efetuados pelo LSPV com o Palio Weekend Elétrico e diversos veículos indicaram que os efeitos da tensão, da corrente e do fator de potência ao longo do processo de recarga resultam numa forma característica da potência ativa. De fato, esta se mantém praticamente constante seguida de um decaimento que pode ser aproximado a uma rampa decrescente. Isto é mostrado no gráfico da Figura 2 onde se verifica que o trecho final se reduz a um valor residual, quando então o estado de carga da bateria alcança $100 \%$. Esta forma se mantém alterando-se apenas o período em que a potência se mantém constante em função da menor ou maior energia requerida que é função principalmente da distância percorrida limitada pela capacidade da bateria a qual determina a autonomia do veículo.

Esta constatação permite uma modelagem da curva de recarga de veículos elétricos bastando para sua simulação os testes assinalados e os dados de placa do carregador e do banco de baterias do veículo. Assim, a previsão dos impactos na curva de demanda da rede de suprimento dos veículos elétricos em recarga bastará a superposição das demandas da combinação de veículos pretendidos. Isto é oportuno uma vez que os demais veículos elétricos tais como bicicletas, scooters, etc. que também apresentam o mesmo comportamento de recarga, como mostram os resultados de estudos realizados pelo LSPV com uma bicicleta elétrica cedida pela Ampla Energia e Serviços S.A. e que atualmente faz parte da frota de veículos da Cidade Inteligente Búzios.

Esta concepção foi utilizada neste trabalho para análise da capacidade de transformadores trifásicos típicos de distribuição conectados na alta tensão dos alimentadores de 13,8 kV da Cidade Inteligente Búzios, objeto de análises específicas nas quais se deseja avaliar o suprimento adicional dos veículos elétricos. O processo utilizado para isto foi obtido pelo tratamento da recarga com uma formulação em termos de variáveis discretas para representar a demanda com intervalos de tempo correspondentes à medição convencional dos sistemas elétricos, igual a 15 minutos. Com isto, o tempo máximo de recarga, que equivale à reposição de $100 \%$ do estado de carga da bateria, será um múltiplo de 15, cuja demanda máxima refere-se às características de potência e rendimento do carregador e a energia à capacidade do banco de baterias.

Assim, tomando como referência os valores de energia acumulada (Wh) e de potência média máxima (W) da Tabela 1 foi possível modelar, com auxílio da ferramenta computacional MATLAB, a curva de recarga apresentada na Figura 4 correspondente ao teste efetuado, apresentado na Figura 2 (potência ativa) e que está associado a um tempo de recarga de aproximadamente 53 minutos e um percurso de 9 $\mathrm{km}$.

A modelagem apresentada na Figura 4 se baseia na curva de recarga total da bateria ( 0 a 100\%), onde a potência do último intervalo de 15 minutos se mantém da mesma forma em todas as demais curvas de recarga para diferentes distâncias percorridas. Este procedimento produz resultados mais conservativos quanto menor a distância percorrida em relação à autonomia do veículo. Em consequência, no caso apresentado, se confirma esta observação tendo em vista a comparação com aqueles mostrados na Figura 4, no tocante à energia consumida medida e a estimada, bem como entre o tempo de recarga medido e calculado na modelagem da curva de recarga. Estes resultados foram considerados satisfatórios, para este caso uma vez que correções 
podem ser efetuadas à partir da distância efetivamente percorrida e de uma melhor avaliação do rendimento do carregador do veículo que foi admitido com $95 \%$.

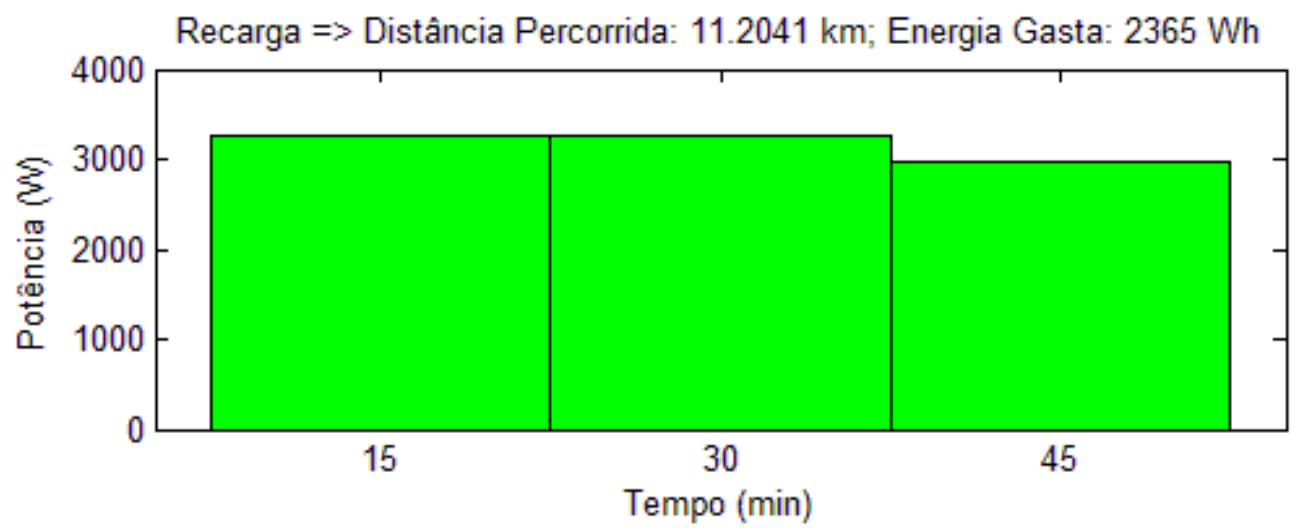

Figura 4 - Modelagem da curva de recarga apresentada na Figura 2

É importante salientar que, assim como a própria curva de recarga, o cálculo da distância percorrida para cada curva também se baseia na curva de recarga total da bateria. Com isso, a distância máxima percorrida na ocasião de uma recarga total é dividida pelo número de intervalos de 15 minutos correspondente a curva de recarga respectiva, assim, cada intervalo está associado à mesma distância percorrida, como se o usuário percorresse sempre a mesma distância a cada 15 minutos. No caso do Palio Weekend em análise, cada intervalo de 15 minutos corresponde a uma distância percorrida de $3,7347 \mathrm{~km}$. Já a energia gasta na recarga é calculada pela área do gráfico da curva de recarga com o tempo em hora, sabendo que, no caso do Palio Weekend, o último intervalo de 15 minutos sempre terá a potência de 2960 W e os demais terão sempre a potência de $3250 \mathrm{~W}$. Assim os valores indicados no título da Figura 4 referemse aos seguintes cálculos:

Distância percorrida $=3 \times 3,7347 \mathrm{~km}=11,2041 \mathrm{~km}$

Energia consumida $=(2 \times 3250 \mathrm{~W}+2960 \mathrm{~W}) \times 0,25 \mathrm{~h}=2365 \mathrm{Wh}$

\section{Comparação de Casos de Recarga de Carros Elétricos}

\subsection{Simulação Determinística}

Com base nas formulações indicadas no item anterior, a Figura 5 apresenta a curva de recarga de um carro elétrico, em verde, e a curva de demanda diária típica de dois dias consecutivos superposta ao suprimento normal de um transformador de 75 kVA, em azul. O impacto da conexão de 18 Palios Weekend Elétricos é representado em verde, após percorrerem a mesma distância média de $75 \mathrm{~km} /$ dia consumindo $80 \%$ da sua autonomia. Tais veículos simulam a frota de uma empresa de prestação de serviços de entrega cujos carros realizam a recarga noturna em garage utilizando-se da tarifa verde, portanto, com um custo bem menor à noite. 

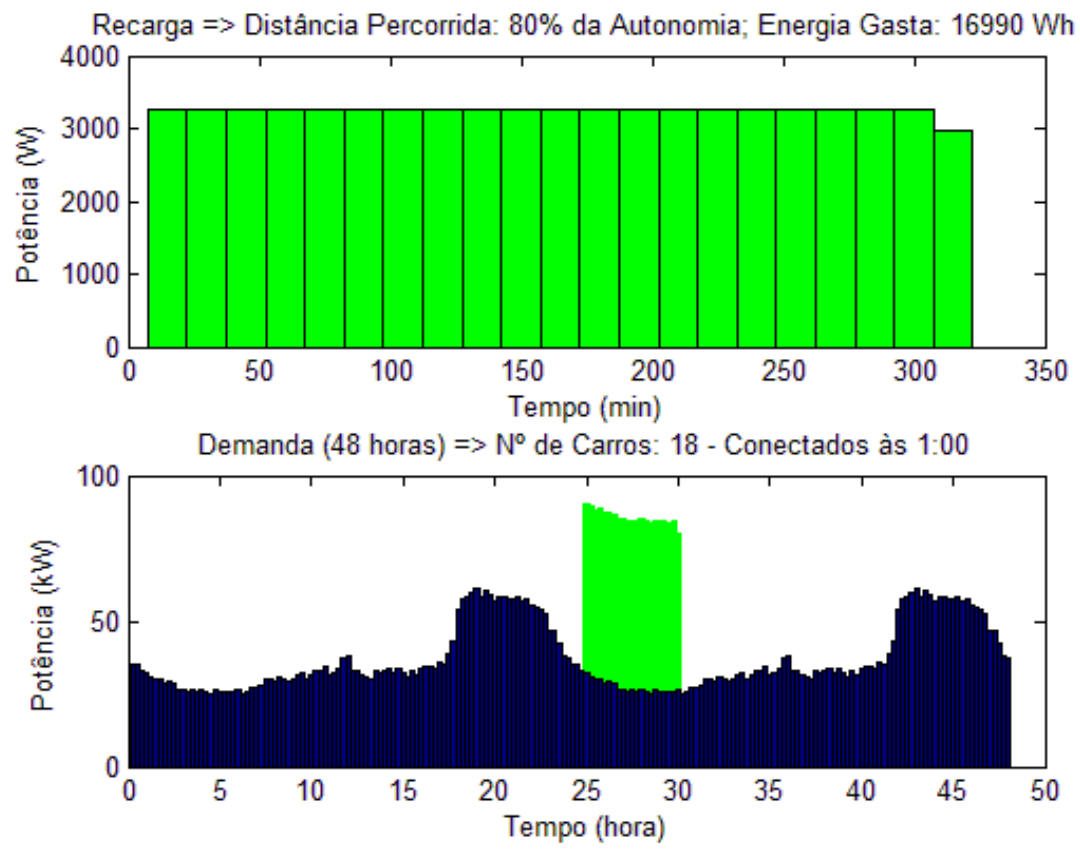

Figura 5 - Curva de recarga do carro e curva de demanda com 18 carros

Nesta análise foram admitidas condições conservativas considerando-se a recarga simultânea dos carros a partir de 1 hora da madrugada. De acordo com a Figura 5, foram obtidos os seguintes resultados:

- Distância total percorrida pela frota - $1411,7 \mathrm{~km}$

- Energia total de recarga da frota - 305,8 kWh

- Demanda máxima do transformador com a frota - 90,5 kW $(98,4 \mathrm{kVA})$

- Instante em que ocorreu a demanda máxima - 1:00 h

Observe-se que mesmo tendo sido iniciada a recarga da frota fora do horário de ponta, à 1:00 h da manhã, ainda assim resulta uma sobrecarga de 31,2\% no transformador admitindo-se um fator de potência indutivo igual a 0,92. A situação mais realista, em geral, corresponde à recarga realizada de forma aleatória com relação à distância percorrida e ao horário de conexão. Este último poderá ser coordenado pelo sistema automático do ambiente das redes inteligentes de energia de forma dialogar com as necessidades previstas pelo cliente sem exceder o carregamento máximo disponível.

\subsection{Simulação Estocástica da Recarga Considerando a Distância Percorrida como Variável Aleatória}

A simulação da recarga de veículos elétricos com diferentes estados de carga das baterias em função das diferentes distâncias percorridas foi procedida com a ferramenta computacional MATLAB considerando uma função densidade de probabilidade seguindo o comportamento de uma lognormal truncada à direta devido ao valor finito da autonomia do veículo associado à capacidade da bateria. As equações correspondentes são descritas em 4.2.1 e 4.2.1. 


$$
\begin{aligned}
& \mu=\log \left(\frac{m^{2}}{\sqrt{v+m^{2}}}\right) \\
& \sigma=\sqrt{\log \left(\frac{v}{\sqrt{m^{2}+1}}\right)}
\end{aligned}
$$

Onde $\mu$ e $\sigma$ são a média e o desvio padrão, respectivamente, da distribuição normal associada, as variáveis $m$ e $v$ são a média e a variância, respectivamente, da distribuição lognormal, elas são funções de $\mu$ e $\sigma$, de acordo com as equações 4.2.3 e 4.2.4, respectivamente.

$$
\begin{aligned}
& m=\exp \left(\mu+\frac{\sigma^{2}}{2}\right) \\
& \left.v=\exp \left(2 \mu+\sigma^{2}\right) \exp \left(\sigma^{2}\right)-1\right]
\end{aligned}
$$

Para a simulação em questão, a média da lognormal corresponde à quantidade de intervalos de 15 minutos da curva de recarga, e a variância, ao quadrado da quantidade de intervalos de 15 minutos. Os valores adotados para as variáveis são:

- Média da Lognormal: $m=48,55 \mathrm{~km}$

- Variância: $v=48 \mathrm{~km}^{2}$

Com isso, tem-se:

- Média da Normal: $\mu=2,44$

- Desvio Padrão: $\sigma=0,5$

Para esta simulação foram feitos 3000 sorteios. Neste caso, cada carro percorre uma distância diferente, mas todos ainda são conectados ao mesmo tempo à 1:00 h. A Figura 6 apresenta uma amostra da simulação da distribuição das distâncias percorridas pelos 18 carros da frota. A Figura 7 mostra a demanda média dos veículos e a do transformador com a recarga da frota.

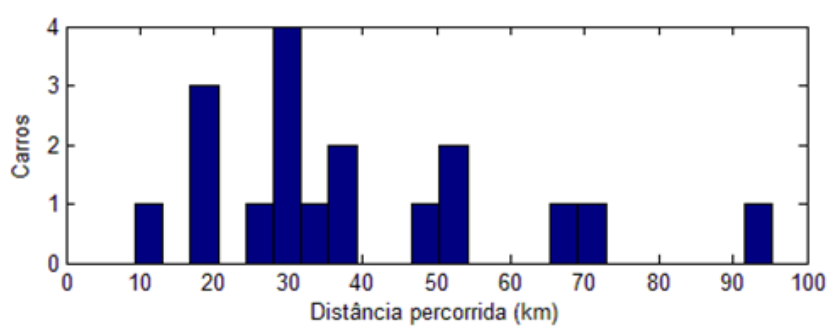

Figura 6 - Amostra da distribuição lognormal da distância percorrida pela frota

De acordo com os gráficos das Figuras 6 e 7, foram obtidos os seguintes resultados:

- Número de veículos que percorreram a distância máxima - 4 carros

- Distância máxima percorrida pelos 4 carros - 29,9 km 
- Distância total percorrida pela frota - 705,8 km

- Energia total de recarga da frota - 143,6 kWh

- Demanda máxima do transformador com a frota - 90,5 kW (98,4 kVA)

- Instante em que ocorreu a demanda máxima - 1:00 h

- Fator de diversidade da energia de recarga $\left(F D_{e}\right)$ :

$F D_{e}=\frac{\text { Energia Total de Recarga da Frota }(\text { Esperada })}{\text { Energia Total de Recarga no Caso Determinístico }}=\frac{143,6}{305,8}=0,47$

- Fator de diversidade da distância percorrida $\left(F D_{d}\right)$ :

$F D_{d}=\frac{\text { Distância Total Percorrida pela Frota }(\text { Esperada })}{\text { Distância Total Percorrida no Caso Determinístico }}=\frac{705,8}{1411,7}=0,50$
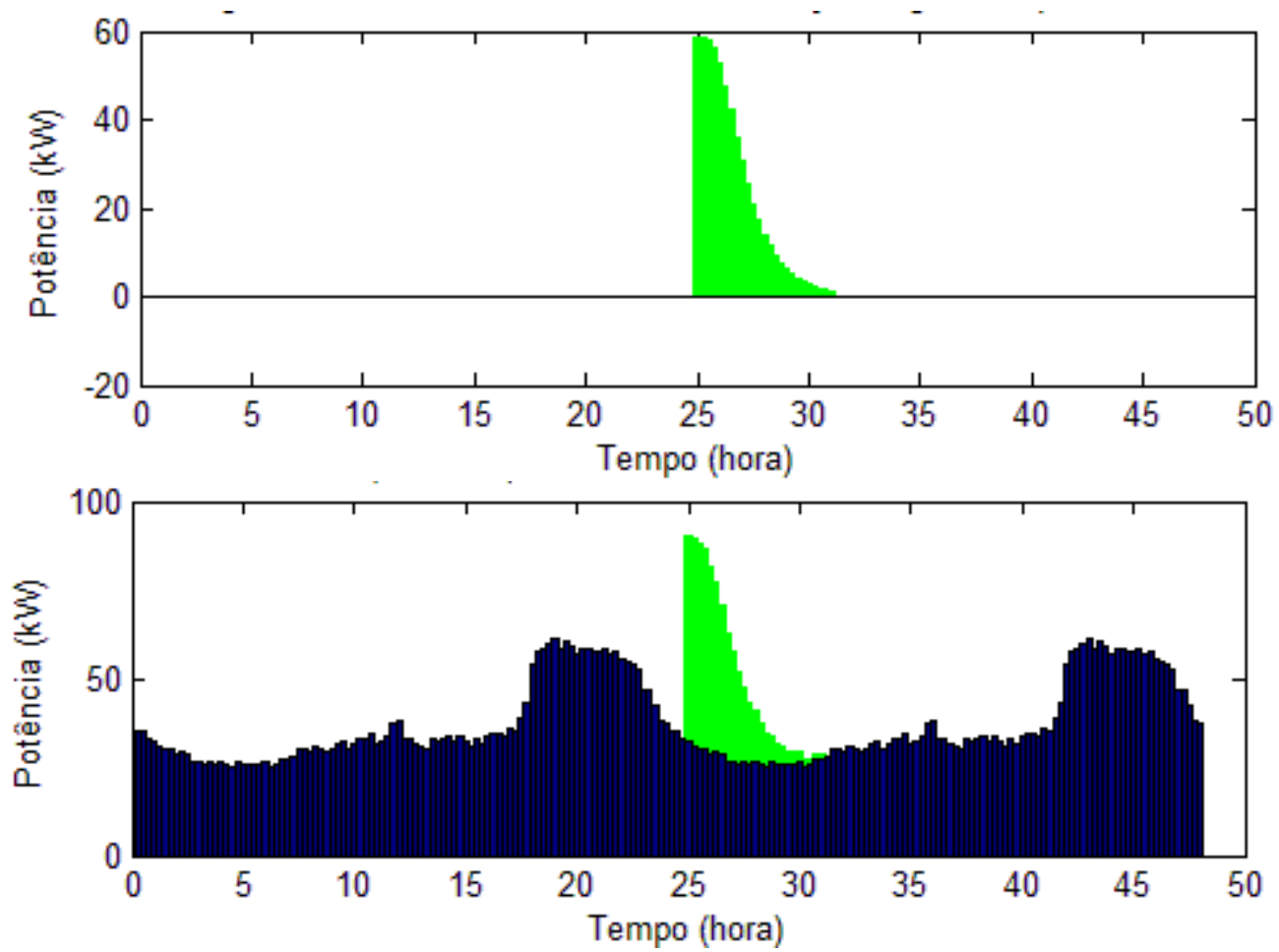

Figura 7 - Demanda média da frota e seu impacto no transformador

Nesta simulação ocorre a mesma sobrecarga do caso determinístico por ter o mesmo número de carros conectados no instante da conexão simultânea dos veículos à 1:00 h, porém o tempo de sobrecarga e a energia consumida reduziram-se consideravelmente evidenciando um impacto de menor gravidade no transformador, uma vez que a elevação de temperatura deste equipamento não seria tão alta. Constatase a coerência da simulação uma vez que o efeito aleatório da distância percorrida afeta a energia consumida no processo de recarga.

A distância percorrida considerada como variável aleatória fez com que a energia total de recarga da frota se reduzisse para $47 \%$ da do caso determinístico, conforme apresentado no cálculo do $F D_{e}$. Além disso, a distância total percorrida pela frota se reduziu para $50 \%$ da do caso determinístico, como pode ser verificado pelo cálculo do $F D_{d}$. 


\subsection{Simulação Estocástica da Recarga Considerando o Instante da Conexão como Variável Aleatória}

Em geral, os usuários não conectam seus veículos elétricos ao mesmo tempo à rede de energia para recarregá-los. Desta forma, para simular a recarga de veículos elétricos conectados em instantes diferentes à rede foram mantidas as mesmas distâncias percorridas do caso determinístico descrito no item 4.1 para efeito de comparação. A modelagem também foi realizada com a ferramenta computacional MATLAB, considerando uma função densidade de probabilidade seguindo o comportamento de uma lognormal, cujas equações são as mesmas do item 4.2. Para esta situação, 18 carros percorrem a mesma distância correspondente a utilização de $80 \%$ de sua autonomia com cada carro sendo conectado à rede em horários distintos.

Nesta simulação a média da lognormal corresponde ao ponto de conexão na curva de demanda, referenciados como "o intervalo de 15 minutos da curva de demanda". A variância corresponde ao quadrado da quantidade de intervalos de 15 minutos. Os valores adotados para as variáveis são:

- Média da Lognormal: $m=6: 45 \mathrm{~h}$

- Variância: $v=315,9 \min ^{2}$

Com isso, tem-se:

- Média da Normal: $\mu=3,11$

- Desvio Padrão: $\sigma=60 \%$

Para esta simulação foram feitos 2000 sorteios. A Figura 8 apresenta a curva de demanda da recarga de um veículo. A Figura 9 ilustra a amostra da distribuição lognormal do horário de conexão dos carros Na sequência, a Figura 10 refere-se à demanda da frota da recarga dos veículos elétricos em recarga e a figura 11 ilustra a superposição da demanda da recarga da frota ao carregamento do transformador.

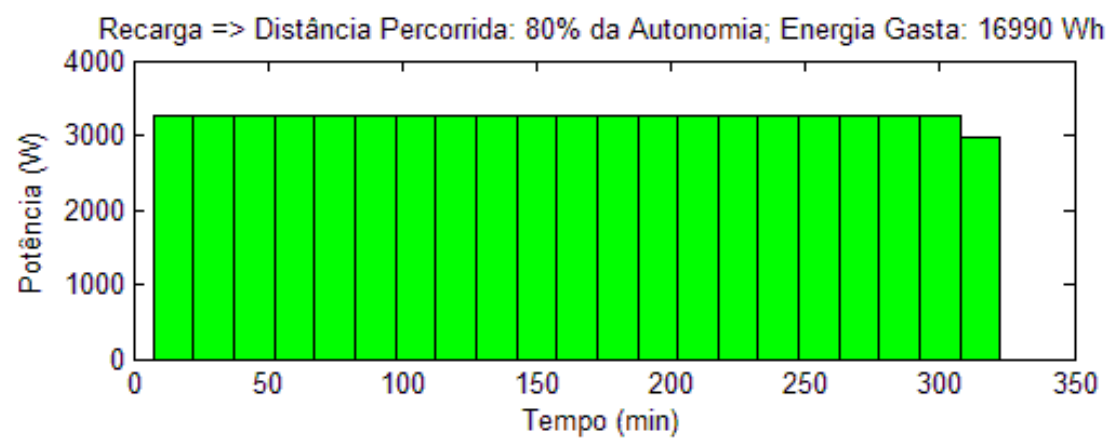

Figura 8 - Demanda da recarga de um carro 


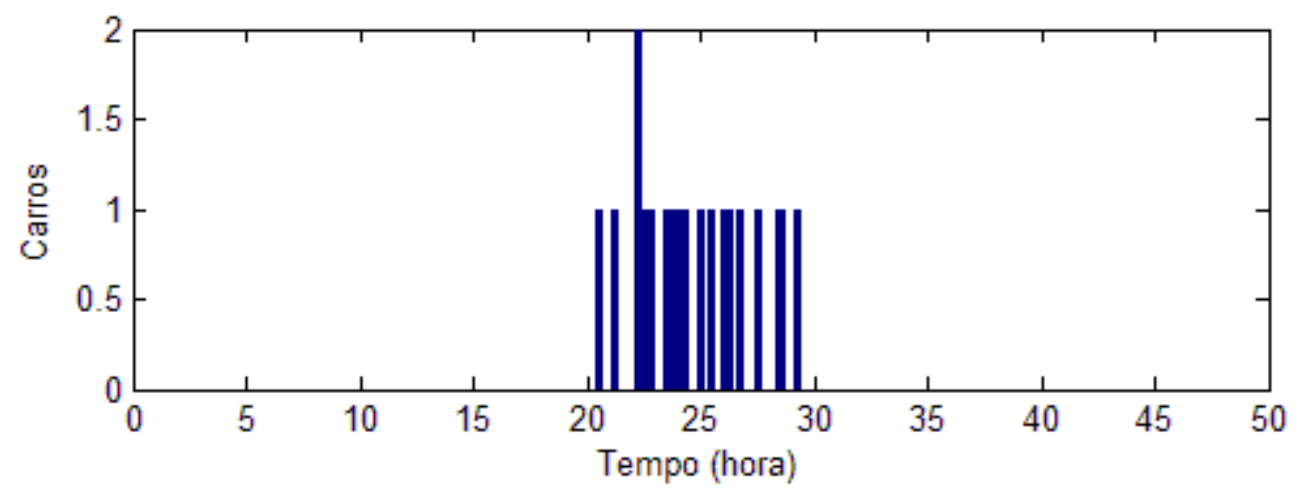

Figura 9 - Amostra da distribuição lognormal do horário de conexão dos carros

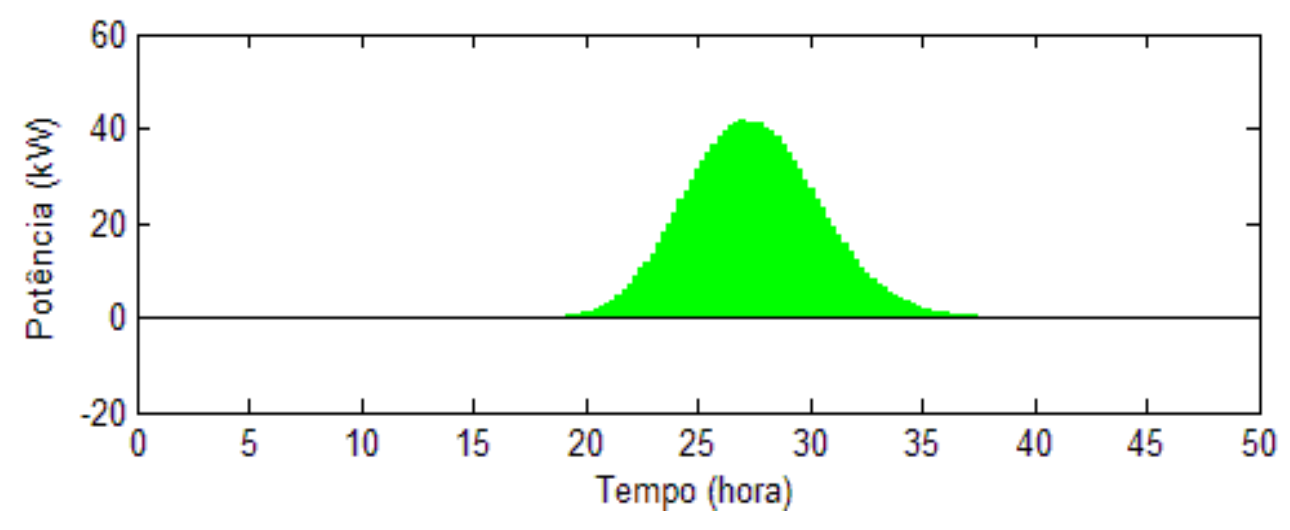

Figura 10 - Demanda da frota da recarga dos veículos elétricos em recarga.

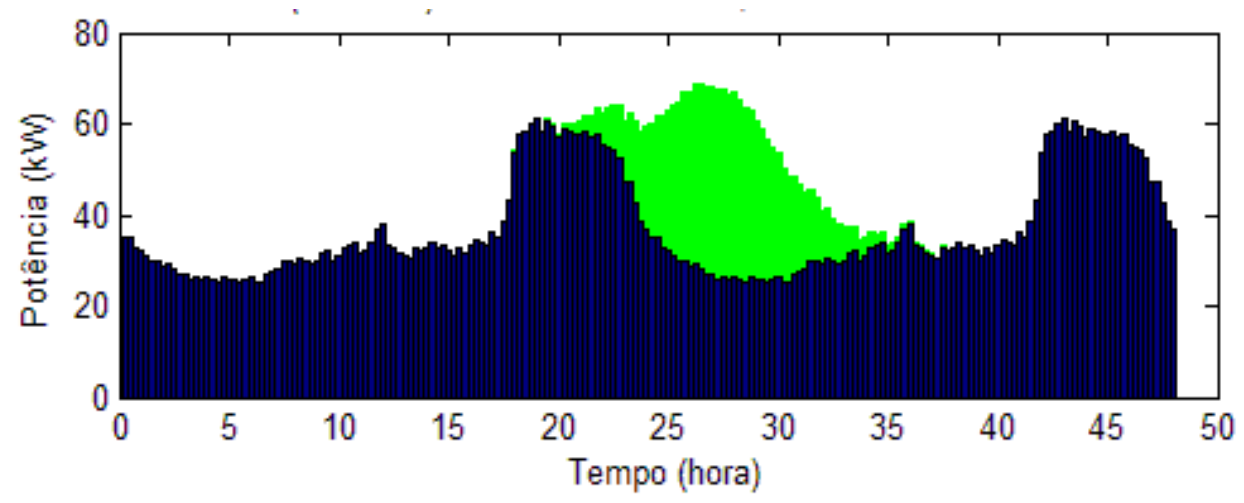

Figura 11 - Superposição da demanda da recarga ao carregamento do transformador.

De acordo com as Figuras 10 e 11 foram obtidos os seguintes resultados:

- Maior número de veículos conectados ao mesmo tempo - 2 carros

- Horário do maior número de conexões - 22:15 h

- Distância total percorrido pela frota - $1411,7 \mathrm{~km}$

- Energia total de recarga da frota $-305,8 \mathrm{kWh}$

- Demanda máxima do transformador com a frota - 68,7 kW (74,7 kVA)

- Instante em que ocorreu a demanda máxima - 2:30 h

- Fator de diversidade da energia de recarga $\left(F D_{e}\right)$ :

$F D_{e}=\frac{\text { Energia Totalde Recarga Esperada }}{\text { Energia Total Determinística }}=\frac{305,8}{305,8}=1$ 
- Fator de diversidade do horário de conexão $\left(F D_{h}\right)$ :

$F D_{h}=\frac{\text { Maior } \mathrm{N}^{\mathrm{o}} \text { de Veículos Conectados no MesmoInstante }}{\mathrm{N}^{\mathrm{o}} \text { de Veículos Conectados no Caso Determinístico }}=\frac{2}{18}=0,11$

Neste caso não ocorre a sobrecarga no transformador. A demanda máxima com a frota não ultrapassou a sua capacidade de $75 \mathrm{kVA}$, indicando que o horário de conexão como uma variável aleatória tem efeito decisivo na demanda do transformador.

De forma também coerente constata-se que a distância total percorrida pela frota e a energia total de recarga consumida apresentaram valores idênticos ao caso determinístico do item 4.1 uma vez que em ambos os casos há o mesmo número de veículos e as mesmas distâncias são percorridas.

Tornar o instante de conexão uma variável aleatória, mantendo-se a mesma distância percorrida do caso determinístico, fez com que a energia total de recarga da frota se mantivesse inalterada, como pode ser verificado pelo cálculo do $F D_{e}$. Já o maior número de veículos conectados no mesmo instante se reduziu para $11 \%$ da do caso determinístico, conforme apresentado no cálculo do $F D_{h}$.

\subsection{Precisão das Estimativas}

As estimativas oriundas das simulações estocásticas se mostram bem precisas através dos cálculos dos coeficientes de variação $\beta$, conforme indicado na Figura 12, na qual são ilustrados os valores de $\beta$ das demandas obtidas em a relação às distâncias percorridas, à esquerda, e ao horário de conexão dos veículos, à direita, respectivamente.

$$
\beta=\frac{\sqrt{\text { variância da demanda/número de simulações }}}{\text { demanda média }}
$$
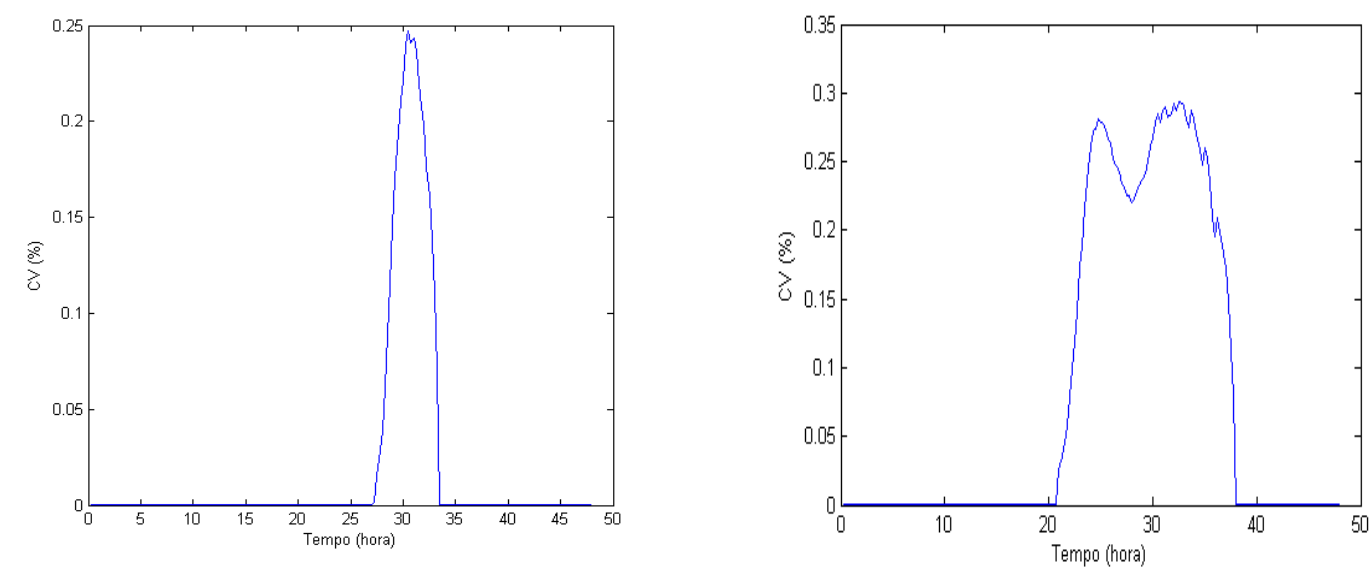

Figura 12 - Coeficientes de variação relativos à precisão das demandas médias

\section{Conclusões}

Os procedimentos propostos nos testes descritos demonstraram a viabilidade para estabelecer metodologias visando estimar o impacto da penetração dos veículos elétricos rodoviários a bateria nas redes de distribuição. Verifica-se que se dispondo de 
parâmetros usuais das redes elétricas e dos dados de placa do carregador e da bateria, obtém-se um resultado decisivo em termos operacionais e de planejamento uma vez que os veículos elétricos apresentam características que são obtidas através de testes típicos de recarga. O trabalho destaca a importância da introdução das redes inteligentes de energia, mostrando que neste ambiente os automatismos previstos otimizam o aproveitamento conveniente das folgas existentes nas curvas de demanda dos transformadores.

Ressalta-se a importância desta modelagem que pode ser utilizada em estudos de dos sistemas de distribuição que visem o atender o mercado de reabastecimento do transporte rodoviário através da penetração dos veículos elétricos de desempenho energético e ambiental superiores aos tradicionais e com afinidade às futuras redes inteligentes de energia.

A diversidade da matriz energética brasileira é adequada a penetração de veículos elétricos rodoviários a bateria que carecem de políticas públicas voltadas para as questões tributárias que impõem atualmente $25 \%$ de imposto sobre produtos industrializados e que inviabilizam o seu ingresso no mercado. A energia disponível internamente pela economia de combustíveis é suficiente para ser direcionada à produção de eletricidade e, conseqüentemente, ao suprimento à propulsão veicular elétrica e ainda oferece a opção de transformá-la em divisas uma vez que, em geral, um veículo elétrico á bateria consome cerca de $1 / 3$ da energia expressa em $\mathrm{MJ} / \mathrm{km}$ de um similar a combustão interna

\section{Agradecimentos:}

Os autores expressam seus agradecimentos à Fundação Carlos Chagas Filho de Amparo à Pesquisa do Estado do Rio de Janeiro - FAPERJ pelo suporte a este trabalho bem como à Agência Nacional de Energia Elétrica - ANEEL e a empresa Ampla Energia e Serviços S.A. pela oportunidade de participação no projeto Cidade Inteligente Búzios.

\section{Referências Bibliográficas}

FREUND, J.E.. \& MILLER, I. Probability and Statistics for Engineers, Englewood Cliffs, New Jersey: Prentice Hall, 1965.

PECORELLI PERES, L.A.; PESSANHA, J.F.M.; PEÇANHA, M.L.P.; TARGUETA, D.; BARRETO, A.; MEDEIROS, M.M.B.A. Test Procedures and Measurements for Recharge Evaluation of Battery Electric Vehicles in Power Concessionaires in Brazil. In: EVS 24 The 24th International Battery, Hybrid and Fuel Cell Electric Vehicle Symposium et Exhibition, 2009, Stavanger.

PECORELLI PERES, L.A.; PEÇANHA, M.L.P.; KREMPSER, A.R.; WINDSON B.P.; PACHECO, O.C.; CORREIA, W.F.; PULLIG, T.F.; GOMES, V.S.M.; SOARES, F.R. Ensaios de sistemas de recarga de veículos elétricos com vistas à mobilidade urbana e o planejamento de redes de distribuição; XXI Seminário Nacional de Distribuição de Energia Elétrica, Santos, Brasil, 2014.

SERRA, J.V.F. Electric vehicles - technology, policy and commercial development, New York: Earthscan, 2012. 